\title{
Post-surgical Ischaemic Myelopathy
}

\author{
James L. Stutesman, M.D., James M. Houston, M.D., Douglas A. Wayne, \\ M.D. \\ Department of Rehabilitation Medicine, Medical College of Virginia, Richmond, \\ Virginia, U.S.A. Associated with Virginia Spinal Cord Injury System
}

\section{Summary}

Ischaemic myelopathy is an infrequent but well-known cause of spinal cord injury. While the overall incidence of neurological injury following thoraco-abdominal aortic surgery is low (1-14\%), procedures requiring surgical cross-clamping of the aorta have been reported as the major cause of ischaemic cord injury (31\%). Little has been reported regarding the clinical and functional outcomes of these injuries. Three patients with a non-penetrating aortic injury who showed evidence of ischaemic cord injury within 72 hours of surgical cross-clamping of the aorta are presented. Data includes functional assessments, muscle strength testing and electromyographic findings. All three patients showed lower thoracic incomplete motor and sensory spinal cord injuries. These findings suggest that, after a period of neurological improvement, a plateau phase is reached at approximately 3 months post injury after which no significant gain in muscle strength is made. All patients were functionally independent and able to ambulate using a straight cane.

Key words: Ischaemic myelopathy; Aortic injury; Lumbosacral plexopathy.

\section{Introduction}

Spinal cord injury due to ischaemia has been well reported in medical literature. (Foo, 1983; Dodson, 1983; Foo, 1981; Szilagyi, 1978; Ferguson, 1975; Brewer, 1972; Herrick, 1971; Edmondson, 1970; Coupland, 1968; Garland, 1966; Weisman, 1944). The most frequent causes of this type of injury has recently been reported to be procedures requiring cross-clamping of the aorta. (Kim, 1985). The incidence of post-surgical spinal cord injury is reported as being between 1 to $14 \%$ (Laschinger, 1984).

\section{Case Reports}

We present 3 cases of postsurgical ischaemic myelopathy occurring after surgical repair of a traumatically disrupted thoracic aorta (Table I). All patients were neurologically intact on examination prior to surgical intervention. No evidence of bony fracture or dislocation of the vertebral column was seen in any patient. No episodes of severe intra-operative hypotension were recorded.

Patient 1 developed neurological deficits over a period of 72 hours postopera- 
Table I

\begin{tabular}{|c|c|c|c|}
\hline & Patient 1 & Patient 2 & Patient 3 \\
\hline Age & 20 years & 42 years & 21 years \\
\hline Sex & Male & Male & Male \\
\hline Injury & $\begin{array}{l}\text { Motor vehicle accident } \\
\text { with aortic rupture, no } \\
\text { neurological deficit. }\end{array}$ & $\begin{array}{l}\text { Motor vehicle accident } \\
\text { with aortic rupture, no } \\
\text { neurological deficit. }\end{array}$ & $\begin{array}{l}\text { Motor vehicle accident } \\
\text { with aortic rupture, no } \\
\text { neurological deficit. }\end{array}$ \\
\hline Length of Surgery & 5 hours & 3 hours & 4 hours 25 minutes \\
\hline $\begin{array}{l}\text { Length of Aortic } \\
\text { Clamping }\end{array}$ & 39 minutes & 53 minutes & Unknown \\
\hline $\begin{array}{l}\text { Days Post-injury } \\
\text { Transferred to } \\
\text { Rehabilitation Center } \\
\text { (Average 13) }\end{array}$ & 16 & 10 & 13 \\
\hline $\begin{array}{l}\text { Length of Stay in } \\
\text { Rehabilitation Centre } \\
\text { (days) (Average 39) }\end{array}$ & 6 & 28 & 89 \\
\hline $\begin{array}{l}\text { Neurological Deficits } \\
\text { at time of Admission to } \\
\text { Rehabilitation Centre. }\end{array}$ & $\begin{array}{l}\text { Lower thoracic motor } \\
\text { incomplete sensory } \\
\text { intact }\end{array}$ & $\begin{array}{l}\text { Lower thoracic motor } \\
\text { incomplete sensory } \\
\text { intact }\end{array}$ & $\begin{array}{l}\text { Lower thoracic motor } \\
\text { incomplete sensory } \\
\text { incomplete }\end{array}$ \\
\hline
\end{tabular}

tively while patients 2 and 3 showed deficits immediately after surgery. No evidence of hematoma formation or other type of compression of the spinal cord could be found in any of the cases.

The patients were transferred to the rehabilitation unit when medically stable and began a comprehensive rehabilitation program. At the time of transfer the patients were found to have lower thoracic incomplete spinal cord lesions with motor deficits much greater than sensory deficits. Only patient 3 showed marked sensory and proprioceptive deficits. None of the patients have developed significant spasticity, remaining slightly hypotonic and hyporeflexic in the lower extremities. All patients initially required intermittent bladder catheterisation but were subsequently able to achieve balanced bladders. Patient 3 has reported the inability to achieve an erection while patient 2 complained of problems with premature ejaculation. Patient 1 reported no sexual dysfunction. No patient has had difficulty with bowel management.

\section{Results}

Recovery of one to two grades of muscle strength was seen in isolated muscle groups early in the rehabilitation process. While some muscle groups underwent rapid recovery others made no improvement and began to show atrophy. In those muscle groups which showed improvement, the greatest return of muscle strength was achieved within the first 3 months of injury. Some further recovery was seen up to 6 months post-injury but despite continued therapy, and highly motivated patients, little additional improvement in muscle strength was attained. At the time of discharge all patients were able to ambulate independently using one or two straight canes, though patient 3 also required bilateral kneeankle-foot orthosis and the use of a wheelchair for long distances.

Each patient successfully returned to his premorbid educational or employment activity after discharge. Each patient was seen for follow-up at approximately 3 months, 6 months and 1 year after injury. 
Table II Electrodiagnostic Studies

\begin{tabular}{|c|c|c|c|}
\hline & Patient 1 & Patient 2 & Patient 3 \\
\hline Time Post Injury & 11 months & 8 months & 12 months \\
\hline Nerve Conduction & Normal & Normal & Normal \\
\hline \multicolumn{4}{|l|}{ Studies } \\
\hline \multicolumn{4}{|l|}{ Distal Motor } \\
\hline \multicolumn{4}{|l|}{ Latency } \\
\hline Distal Sensory & Absent & Normal & Prolonged \\
\hline \multicolumn{4}{|l|}{ Latency } \\
\hline \multirow[t]{2}{*}{ F-waves } & Absent peroneal & Normal peroneal & Absent peroneal \\
\hline & Prolonged tibial & Absent tibial & Prolonged tibial \\
\hline H-reflex & Absent bilaterally & Normal bilaterally & Normal bilaterally \\
\hline Electromyography & Normal & Normal & Normal \\
\hline $\begin{array}{l}\text { Paraspinal Muscles } \\
\mathrm{L}_{1}-\mathrm{S}\end{array}$ & & & \\
\hline Lower Extremity & Abnormal * & Abnormal * & Abnormal * \\
\hline Muscles & & & \\
\hline
\end{tabular}

* Variable findings of increased insertional activity, increased spontaneous rest activity, decreased recruitment patterns, increased polyphasic motor unit action potentials and various size amplitudes ranging up to $15 \mathrm{mV}$.

Nerve conduction studies and electromyographic examinations were performed during various follow-up examinations (Table II). While the nerve conductions studies showed some abnormalities such as the absence of the $\mathrm{H}$-wave bilaterally in patient 1 , and the prolongation or absence of the F-waves in the peroneal and tibial nerves of all the patients, distal motor latencies were found to be essentially normal. Decreases in the amplitudes of the evoked motor response were seen in the most severely affected muscles consistent with muscle atrophy. Electromyographic findings showed widespread polyphasic motor potentials, consistent with incomplete injury with signs of re-innervation. Recruitment patterns were highly variable with no voluntary recruited motor units seen in the biceps femoris muscles bilaterally in patients 2 and 3. Electromyographic studies of the $\mathrm{L}_{2}-\mathrm{S}_{1}$ paraspinal muscles bilaterally showed no abnormalities in any of the patients.

\section{Discussion}

Little has been reported regarding the natural history of post-surgical ischaemic cord injury. Several isolated cases similar to our patients have been reported, (Foo and Rossier, 1983; Garland, 1966) but little follow-up information is available for these patients. The clinical course followed by our patients led us to question the pathological basis of their neurological deficits. The electromyographic findings of normal paraspinal muscles suggests a more functional spinal cord than we expected with the persistent hypotonia and hyporeflexia. In light of essentially normal peripheral nerve conduction studies, recruitment patterns seen during the electromyographic exams were suggestive of bilateral lumbosacral plexus injury. These findings have led us to postulate that these patients' deficits may not be due to injury exclusively at the spinal cord level but may involve significant ischaemic injury at a more peripheral level, most likely at the lumbosacral plexus. These findings may have important prognostic significance for any further neurological recovery in this group. We plan sequential elect- 
rodiagnostic studies and continued long term follow up of these patients. While no firm conclusions can be drawn from such a small group of patients, we believe further investigation of the pathology and natural history of these types of injuries is needed.

\section{References}

BREWER LA, III 1972 Spinal cord complications following surgery for coarctation of the aortic. Journal of Thoracic Cardiovascular Surgery 64:368-381.

CaRlson DE, Karp RB and Kouchoukos, NT 1983 Surgical treatment of aneurysms of the descending aorta: An analysis of 85 patients. Annals of Thoracic Surgery 35:58-69.

Coupland GA and Revene TS 1968 Paraplegia: A complication of excision abdominal aortic aneurysm. Surgery Vol. 64:878.

CRAWFord SE, FENSTERmacher JM, Richardson W and SANDiford, F 1970 Reappraisal of adjuncts to avoid ischaemia in the treatment of thoracic aortic aneurysms. Surgery Vol 67, No. 1:182-196.

DebaKey ME, et al. 1982 Dissection and dissecting aneurysms of the aorta: Twenty-year followup of five hundred patients treated surgically. Surgery Vol. 92, No. 6:1118-1134.

Di ChIRo G and DoppManN TL 1969 Paraplegia after resection of aneurysm. NEJM 281:299.

DoDSON EW and LANDAU WM 1983 Motor neuron loss due to aortic clamping in repair of coarctation. Neurology Vol 23:239-542.

EDMONDSON HT and GINDIN RA 1970 Paraplegia as a complication of abdominal aortic resection. American Journal of Surgery 36:383.

FERGUSON LR, et al. 1975 Spinal ischaemia following abdominal aortic surgery. Annals of Surgery $181: 267$.

Foo D and Rossier AB 1983 Anterior spinal artery Syndrome and its natural history. Paraplegia $21: 1-10$.

Foo D, Subrahmanyan TS and Rossier AB 1981 Post-traumatic acute anterior spinal cord syndrome. Paraplegia 19:201-205.

Garland H, GreEnberg J and Harriman DG 1966 Infarction of the spinal cord. Brain 89:645662.

HARDY AG 1977 Cervical spinal cord injury without boney injury. Paraplegia Vol. 14:296.

HerRick MK and Mills PE March 1971 Infarction of the spinal cord. Archives of Neurology Vol. 24.

KIM SW GoRdon S and KIM RC 1985 Ischemic myelopathy. Abstract read to the American Paraplegic Society Meeting.

LASCHINGER JC, et al. 1984 Prevention of ischaemic spinal cord following aortic cross-clamping: Use of corticosteroids. Annals of Thoracic Surgery Vol. 38, No. 5:500-507.

LASCHINGER JC, et al. 1984 Intraoperative identification of vessels critical to spinal cord blood supply-Use of somatosensory evoked potentials. Curriculum of Surgery March-April.

LASCHINGER JC et al. 1982 Detection and prevention of intraoperative spinal cord ischaemia after cross-clamping of the thoracic aorta: Use of somatosensory evoked potentials. Journal of Surgery Vol. 92, No. 6:1109-1117.

LESSER RP et al. 1986 Postoperative neurological deficits may occur despite unchanged intraoperative somatosensory evoked potentials. Annals of Neurology Vol. 19:22-25.

NAJAFi $\mathrm{H}$ et al. 1982 Descending aortic aneurysmectomy without adjuncts to avoid ischaemia. Annals of Thoracic Surgery Vol. 30:326-335.

Szilagyi DE, Hageman JH, Smith RF and Elliott, JP 1978 Spinal cord damage in surgery of the abdominal aorta. Journal of Surgery Vol 83, No. 1:38-56.

WEISMAN AD and ADAMS RD 1944 The neurological complications of dissecting aortic aneurysms. Brain 67:69-92. 